\title{
12 The intermediality of performance
}

\author{
Per Bäckström, Heidrun Führer and Beate Schirrmacher
}

In the street, you see a person standing on a box, motionless like a statue. When someone throws a coin into a hat on the pavement in front of her, she starts to move. The same evening at a bar, a young man gets onto a makeshift stage, grabs the microphone and starts to talk. After only a few moments, the audience responds by laughing. In the city's theatre, the whole audience listens silently to how Hamlet, Prince of Denmark, struggles with the question 'to be or not to be'. Meanwhile, in the concert arena, a pop artist sings his or her latest songs in a show that includes lights, different costumes, dance and video in front of thousands of cheering fans.

Pantomime, stand-up comedy, drama and pop music concerts are different experiences and follow different conventions, but they are all artistic performances that take place in a marked, specific performative space: a stage, a theatre or an arena. Even in everyday life, people perform to reinforce and communicate identity in front of an audience. The so-called performative turn in social sciences and the humanities discovered the role of performance in all kinds of human interactions. In a way, performance is everywhere and '[a]ll the world's a stage', as Shakespeare wrote in his play As you like it (written ca. 1600). Performance studies explores all kinds of events, from theatre performances and artistic activities outside institutional framing to sporting contests, ceremonies, informal gatherings, everyday rituals and daily interaction. This performative aspect of everything we do and say has become even more prominent in social media interaction today (see Chapter 16).

In this chapter, however, we will focus on performance as an aesthetic or communicative event that unfolds at a specific time and in a specific space and where at least one person performs a series of movements that we perceive as meaningful in front of an audience. In traditional theatre, the audience is accustomed to sitting and watching passively and silently. However, when we look at the audience of a pantomime acted out in the street, a stand-up comedy act, a festival or a football match, we understand how the audience takes an active part in the construction of a performance. The co-presence of performer and audience creates a performative space that is set apart from the social world. Performance scholar Jill Dolan highlights the utopian potential of live performance as 'a place for people to come together, embodied and DOI: $10.4324 / 9781003174288-15$ 
passionate, to share experiences of meaning-making and imagination that can describe or capture fleeting intimations of a better world' (Dolan 2005, p. 2).

However, it is not only people who come together in a performance, but also many different kinds of materialities and media. In the unique moment of performance that unfolds in time and space, the performer interacts with an audience but also with other objects: props such as the famous skull that Hamlet holds in his hand or technical devices such as the microphone in a stand-up act. In this chapter, we will look closely at how different kinds of bodies and objects interact in a performance and at how the presence and emergence of an event interact with mediation and transmediation. Pantomimes, stand-up comedy acts, drama and music concerts can be understood as different qualified media types that take place in the context of different architectural framings that already in themselves indicate which conventions are at play, what kind of performance the audience should expect and what kind of response is expected from the audience (see also Chapter 14).

We explore the interaction between performers and technical devices and other basic and qualified media by analysing different kinds of performances of lyrical poetry and their media transformation to YouTube videos and discuss different levels of entanglements by looking at the performance of a football game.

By doing so we want to go beyond Philip Auslander's concept of mediatized performance (Auslander 2008 [1999]). Instead of differentiating between a performance and its mediatization, we explore how mediation and, in many instances, media transformation are part of the performance itself. From an intermedial perspective, mediation and transmediation does not first take place when electronic media of amplification and reproduction come into play. Instead, these aspects already are part of the qualified media type performance. By exploring performance as a qualified medium, we also highlight the importance of performative key concepts such as presence, process and entanglement in all kinds of intermedial relations. This opens up the possibility of considering the performative aspects of other media products as well.

\section{Performance, mediation and performativity}

If we define performance primarily as unfolding in the present moment, and understand media products primarily as tangible material objects, then the performative event and media products appear much more opposed to each other than they actually are. The seemingly clear distinction between presence and representation stems from the ideological need to demonstrate the importance of presence. Performance studies focuses more on the processes that develop a 'transformative power' (Fischer-Lichte 2008) rather than on specific repeatable content that performances communicate as well.

From an intermedial perspective, however, performance can be described as a media product in the form of an event, characterized by its specific spatiotemporality that involves affecting bodies in the sensorial modality. Seen from 
this perspective, performance and mediation seem no longer opposed to each other. Instead, they appear as different aspects of the complexity of communicative situations. Performance can then be described as a qualified media type that combines or integrates many technical devices and basic and qualified media types: bodies interact with, for example, props, screens, speech, text, images, costumes, colours, video and music. In fact, the multimodality of a performance has the potential not only to integrate with but also to transform any other media type, which has provoked the idea that theatre should be understood as a 'hypermedium' (Chapple and Kattenbelt 2006).

In the communicative event of a performance, binary distinctions, such as doing and meaning, presentation and representation, are undermined. Bodies and objects on stage communicate not only by representing things and pretending to carry out acts, but they also communicate by being present and carrying out acts. If we approach performance with binary distinctions, they start to 'oscillate' or 'fold into each other'. This oscillation between concepts that we perceive as being opposed to each other is called performativity and is one of the main characteristics of every act of performance.

\section{Box 12.1 Performativity}

The term performativity originates from linguistics. In the 1950s, the linguist J. L. Austin drew attention to the fact that verbal language is not only about representation of meaning. In his book How to Do Things with Words, Austin (1962) describes how certain words (such as 'to baptize' or 'to marry') not only represent certain acts are also part of the social actions they describe. This performative aspect of language is not only restricted to the relatively small group of performative verbs that Austin draws attention to but is also an aspect of all language use. When we use words, we want to cause (re)actions. A person can say, 'It's cold in here' with the aim of making someone else shut the window. These kinds of speech acts are studied within linguistic pragmatics. The performative aspects of verbal language have been explored further by post-structuralist philosopher Jacques Derrida, who points out how every word we choose carries out a performative act that repeats conventions but also has the potential to change them (Derrida 1988 [1977]). Derrida's philosophical approach to language made it possible for Judith Butler to explore further how we perform gender (and social identity in general) by means of repetition and change (Butler 1990). Performativity has become what Mieke Bal calls a travelling concept (Bal 2002) that changes the perspective from representation of conventional meaning to social acts that are being carried out. Binaries like meaning and doing, representation and presentation, repetition and change are enmeshed and cannot be told apart from each other to the extent that it is neither possible nor productive to clearly separate them (for an overview, see, for example, Bal (2002) or Velten (2016)). 
The concept of performativity highlights how acts of representation are able to change the world around us and made it possible for performance and theatre studies to highlight the performer's presence and his or her acts as an intrinsic part of the performance. Our intermedial approach allows us to explore more in detail the entanglement of presence and representation, of performance and media products, of performativity and intermediality. After all, both performance studies and media studies are interested in the role of material presence in communication, be it the presence of bodies and their interaction or the material presence of objects that we interact with.

Even the concept of a performance as a 'live' event depends on the existence of media products that represent and transmediate performances. Still, there is a difference between a live performance and its representation in other media. However, from an intermedial perspective we see that it is not enough to dismiss the media representation of a performance as just a 'reproduction' or as 'unreal'. Instead, we can explore it as an instance of transmediation. The film clip that you recorded at a concert transmediates basic media types of the performance, but it cannot really transmediate the co-presence of affective bodies, the experience of being there.

In many kinds of performances, different technical media and qualified media types are a deeply integrated part of the live experience. The audience of a rock concert or of a football game are both attending a live event but at the same time gather a lot of their impressions from video screens on or around the stage or pitch. In the light of this, how can we tell where the live performance ends and the media representation begins? And is there a producer of any live performance in the digital age, especially in the social media age, that is not aware that it has the potential to be extended and reproduced beyond the here and now - that it can be filmed and shared instantly?

\section{The performer's body as a medium}

In the study of the intermedial aspects of performance, the live body and its interaction with other technical devices and qualified media types stand in focus. The poet William Butler Yeats (1865-1939) famously asked: 'How can we know the dancer from the dance?' (Yeats 1996). His question illustrates that it is hard to distinguish between the performer's body and what we call in this book the qualified medium of dance. Nor is it easy to understand how the performer's body can act like a medium, which cannot be separated from the presence of a human being per se. ${ }^{1}$ At the same time, we realize that the situation is rather complex, since at least one other medium is involved: the body is not usually moving of its own accord but is seen moving in relation to music of some sort - be it tapping a rhythm with a hand or foot, humming, a musical instrument or an entire orchestra.

Hence, the material human body is the main medium we must focus on when we are analysing a performance. But the body also interacts with technical devices like microphones and other basic media types like sounds and 
organized sound, as well as media products of other qualified media types like music, or film. Because of this, the analysis becomes more and more complex, and in the end, we have to acknowledge that an increasing number of media constitutes a particular performance.

It is clearly not easy to come to terms with the idea of the body being a medium in a performance. To put it simply, the perspective of performance studies on the body corresponds to what we call in this book a technical medium of display; in contrast, intermedial studies observes the body in all its intermedial aspects and relations, but at the same time, the presence of the body tends to be neglected. At first sight, these look like two mutually exclusive fields of research, but on a closer look, mediation is not necessarily opposed to presence, because the main medium in a performance is the body, and the body is directly connected to questions about presence and authenticity. Amalgamating these two analytical fields is therefore a good idea, because it could introduce a richer analysis focusing on the body, other media and presence. The body is not only a technical medium of display in a performance, but also much more. For example, the body displays the semiotic modality such as the embodied or body-related codes that are needed to experience presence; these codes imply the sensorial modalities of seeing and hearing, for instance, the wearing of long black leather coats and growling respectively in black metal. According to Lars Elleström (2021), the body can be seen as a basic medium in a performance, since we perceive the bodily movements of a performer in a spatiotemporal performative space as meaningful - as a performance by a moving body, which, in this special case, is a qualified medium. When the specific purpose of a performance is to express an aesthetic utterance or a communicative act with the body, the body becomes a technical medium of display. We can communicate multimodally by using the body through clothing, facial expressions, body posture and movements, gestures, our voice, verbal text, etc. The body has a variety of uses, and while those that are driven by nature and instinct have a biological function that is common to all fauna, it also has uses that are more developed in human beings that we will focus on next: orality and gestures (see Box 12.2).

\section{Box 12.2 Bodily performance: Orality and gestures}

Orality refers to both verbal expressions (the actual words) and extra-verbal expressions, such as the pronunciation of these words (intonation, pitch, etc.) and non-verbal sounds, such as guttural expression, expressions of astonishment, hesitation or thoughtfulness ('er ...') and emotions, emotional expression, etc. Verbal language is a complex area of research, but to gain an understanding of the orality of a performance, only a fairly simple question about its function needs to be considered: which words do the performer(s) actually articulate? Extra-verbal expressions and non-verbal sounds have mostly been neglected until recently, both by linguists and 
performance studies scholars, despite the fact that these expressions add value to a performance. In music studies (Barthes (1981) and Frith (2002 [1996)), this phenomenon is receiving increasing attention, which should be self-evident after decades of pop music that includes nonsensical sounds, such as Little Richard's 'A-wop-bop-a-loo-bop-a-wop-bam-boom!' in the song 'Tutti Frutti' (1955). ${ }^{2}$ For an intermedial and performance studies analysis of a performance, it is therefore important to pay more attention to both non-phonetic ('sniffs, lip-smacks, grunts, moans, sighs, whistles, and clicks') and nonsensical expressions (Keevallik and Ogden 2020, p. 1).

By gestures, we mean the non-verbal modes of embodied communication. It is easy to disregard gestures in performance studies, or even to take an approach that views gestures as subordinated to orality, as in traditional linguistics, but such a way of thinking neglects the decisive importance of non-verbal expressions in our communication. The Oxford Latin Dictionary describes gestures as something in-between: "Neither praxis nor poiēsis, Gerere - from which "gesture" is derived - means "to bear", "to carry", but also, "to show", "to reveal", "to perform the function", "to administer an office"' (Glare 1982, p. 762). The philosopher Giorgio Agamben (2018) also sees 'gesture' as the middle way, in between 'to do' (facere) and 'to act' (agere). He explains this by pointing to the importance of gestures in a performance, where they have parity with verbal language: 'Gesture is the name of this intersection between life and art, act and power, general and particular, text and execution' (Agamben 2000 [1996], p. 79). Gestures that have often been regarded as subordinated to speech and of no significance are in fact constitutive of a performance. And gestures not only work with, against or separately from verbal language but also take part in the production of language before it turns into verbal expressions (GoldinMeadow and Alibali Wagner 2013). It is therefore of the utmost importance for an intermedial and/or performance studies analysis of a performance to observe the gestures and posture of the performer(s) (see also Kendon (2004) and Michel Guérin (2011 [1995])).

A bodily performance of any kind is mostly constituted by two main basic media types, orality (verbal and extra-verbal expression) and gestures (nonverbal expression), where gestures can work in tandem with extra-verbal expressions. In a multimodal analysis, these two basic media types could be divided into an even more fine-grained analysis of modes, such as intonation and pitch, hand gestures and body posture, etc. However, even if we sum up these various modes of the basic media types of gesture and orality, we use gesture(s) in this chapter in a broader sense to include movement and posture, because it is practically impossible to distinguish between different parts of nonverbal communication. 
What complicates things when we think about the body as a medium, however, is the fact that we also perceive all kinds of mediated communication through our own bodies And, to complicate things even more, two kinds of bodies are always present at a performance: the body of the performer and the bodies of the audience (see Chapter 14, Box 14.2). This double function is very important, but it also constitutes a challenge when we consider intermedial aspects of a performance, because we have to consider which aspects of the bodily interaction with other media we should focus on - the body as the performing instance or the body as the recipient of sensorial data? Here we will focus on the first aspect, because the second aspect is hard to analyse when the material is a film clip. Rather than postulating that the body is a medium, it's more important to understand how the body can function and be used as a medium, especially if we want to understand how embodied performance presents and interacts and connects with other forms of mediated communication.

\section{Poetry performances}

In this section, we analyse the intermedial interaction between the body and different media in three different poetry performances. In our step-by-step analysis, we explore the following aspects:

1 The presence of the body.

2 The qualifying aspects of the performance.

3 The interaction with other media types and the expansion of the performative space with the use of technical devices and different media.

The first step explores how bodily presence, that is, how the orality and gestures of the performer, contributes to our understanding of the words performed, and here we focus on the body as a basic medium. The second step discusses the qualifying aspects of a performance, that is, aspects that contribute to our initial understanding that what we see and hear is a performance in the first place. The final step includes the interaction with other media types, both those that are 1) part of the performance and thereafter those that are 2) not part of the actual performance, but the technical devices that make it possible for us to observe the performance. While two of the performance analyses focus on the performer, the third analysis looks at the interaction between the performer's body and the audience's bodies. The result of these analyses is the recognition that a performance that at first sight seems fairly uncomplicated almost always involves a more complex intermedial situation.

\section{Different kinds of poetry performance}

We use the term 'poetry performance' in this chapter to serve as an umbrella concept for every performance of a poem (without music), which can be divided into subgenres such as poetry-reading, lyrical performance and spoken- 
word/poetry slams. A 'lyrical performance' is a performance in which the poet does not read the poems from a written text but performs them after having memorized them (Bäckström 2003). Lyrical performance and spoken word are overlapping concepts, but they describe two different strategies that can be illustrated by Lydia Lunch's more inspirational act versus Henry Rollins' memorized performance. The three examples of subgenres noted earlier belong to two different kinds of aesthetic performances. A poetry-reading is a performance that stems from a literary media product. In performance art, however, the media product is a performance that has an aesthetic intention in itself, which makes it an artwork in its own right. A seemingly spontaneous street performance fits this description, and this type of performance art first came into prominence in the 1960s. Lyrical performance and even more so spoken word, which is based on improvisation, are also kinds of performance art.

In poetry performances, in general, there are at least three different ways in which orality and gestures can relate to each other: 1) orality overshadows the gestures, as in many poetry-readings, 2) orality and gestures have equal status, as in lyrical performance and spoken word, and 3) orality is subordinated to the gestures, such as when rock singers growl in death metal and black metal. We will look into these three aspects and their different demands in the context of an intermedial analysis of three poetry performances by the American poets Lydia Lunch, Henry Rollins and Allen Ginsberg, respectively (see Box 12.3). All of the performances have been recorded and published on YouTube.

\section{Box 12.3 Poets}

Allen Ginsberg (1926-97) was one of the main Beat poets who revolutionized the American poetry tradition when they introduced poetry-readings and performances and suggested that they were as important or even more important than the printed poems. Ginsberg is most famous for Howl and Other Poems (1956), but equally important is the title poem in Kaddish and Other Poems (1961).

Lydia Lunch (b. 1959) is an American rock singer (Teenage Jesus and the Jerks, 8-Eyed Spy, the Contortions, solo), actress, poet, spoken-word artist, etc. She has published several books, including Paradoxia (1997) - a kind of autobiography - but her main act is spoken word, regarding which she has released more than 15 recordings.

Henry Rollins (b. 1961) is an American rock singer (Black Flag, Rollins Band), actor, author, poet, spoken-word artist, etc. He has published several books, a selection from them is published in The Portable Henry Rollins (1997), but like Lunch, he prefers spoken word to rock music and has released more than 15 spoken-word records. 


\section{Performance - The body}

In her spoken-word performance of the poem 'Fuck', 3 Lydia Lunch describes the 'meat market' that she welcomes the audience to. The market metaphorically signifies men's obsession with sex, a theme she scorns the audience for, teasing the men in explicit language until one of her last statements: 'you can't afford it, and I'm not selling it'. How do orality and gestures in her performance contribute to our understanding of the poem? Lunch clearly performs her poem, and her enactment seems to rely on improvisation. She is wearing a glittering black dress and bright red lipstick and has dyed bright red hair; that is, she is dressed for this performance in a way that fits with the female gender role she will criticize an instant later. She raises herself with the microphone in her hand and a neutral but nevertheless friendly expression on her face and smiles sweetly towards the audience - or maybe someone among them; the smile, again according to a stereotyped female behaviour, quickly turns audacious and forbearing at the same time. In a few seconds, she has established the necessary presence and contact with the audience, because she has looked and even stared directly at them, and then she starts to recite the poem with an offensive expression on her face. ${ }^{4}$ Here orality and gestures are clearly emphatic, and her obligatory but sarcastic 'Welcome, Ladies and Gentlemen' reveals a wish to shock. She begins as if she wants to introduce somebody else, but instead she presents a powerful self to the audience, a self that does not comply with the expectation that she will display compulsory female behaviour. Instead, she is a strong woman with sexual desires, complaining about men. Her articulation is exaggerated, with excessive lip movements that make her speech both ardent and provocative. Her arm movements are vigorous and she takes up space; that is, she behaves in a way that a woman is not traditionally supposed to behave. Her left arm is either drawn against her chest in a gesture of anger and vitality or is pointing out towards the audience as if she is indicating someone in the audience, challenging the man she has selected. The audience is in shadow; it is only possible to see a line of dark heads in the front row and to hear the audience cheering or mocking her. Her sometimes vulgar expressions and gestures, combined with her explicit poetry, show the audience, and the viewers of the video, a powerful woman. Lunch's performance is deliberately disturbing, as she establishes a stereotyped female gender role only to undermine it profoundly with her orality and gestures.

When Henry Rollins performs his poem 'Family Man', he stands in front of a screen showing slides and confronts the audience with a fierce monologue scorning gender roles. Rollins rages against the family man, who is an incarnation of suburban family life. Rollins' face is seen in a close-up, and at the very start he has his face turned sideways and his eyes closed. The performance is clearly staged, beginning in darkness and ending in light. When the first slide is projected, accompanied by the sound of the projector, he abruptly 'wakes' up, opens his eyes to stare at the audience and then slowly turns his head towards us. A fiery presence is immediately established, even though there 
might be no other audience than the people watching the clip. He starts to recite his poem 'Family Man' and then - probably involuntarily - he blinks for the only time in the whole sequence. The expression 'family man' has a neutral connotation when Rollins uses it, even though it is usually loaded with the positive connotations of a trustworthy husband and father. When Rollins pronounces these two words, his expression, especially the grimace he makes with his mouth and the minimal movement of his eyebrows, changes them from forming a neutral description into an expression of hatred and utter contempt. At the end of the performance, the last slide is projected and then the blank screen takes over, although this is not completely synced with his last words. Rollins' face is then lit up as if by the projector, but the glitch in the syncing reveals that it is probably a second light source. There are not many gestures except his lips pronouncing the words in a sinister and threatening way while he stares at the camera without a single blink (after the first and only one), which means that he is staging himself as a very threatening figure. Rollins has memorized the poem, ${ }^{6}$ and from the very start we focus on his face. In many ways this is a minimal performance; there is not an abundance of movements or other distractions (if we concentrate on his body, although we can only see his face), and in this sense it is a perfect example of a lyrical performance. In fact, he only performs using his face, with orality and a minimum of facial gestures. Even though there is not much movement except for his lips, there are facial expressions that we can interpret as gestures that both change and specify the meaning of the verbal statements. Therefore, the main gesticulation in this performance takes place in Rollins' face, where his mouth and eyebrows are in motion. This makes his facial gestures even more threatening, because they exaggerate the sinister mood of the performance. This is an exemplary illustration of the power of gestures and intonation, because Rollins' gestures change a phrase that can have either neutral or positive connotations into an expression of utter contempt.

Contrary to Lunch and Rollins, Allen Ginsberg read his poems at the Royal Albert Hall in $1965 .^{7}$ But even in this performance of the literary media product of a written text, Allen Ginsberg's orality and gestures have an impact on our understanding of the poetic situation. His reading starts after a prelude, but his performance is already qualified because he is one of a group of poets reading their poems. Ginsberg reads his poems with emphasis. To show that he is a Poet, he reads from sheets of paper he is holding in his right hand, and after a while he picks up a book and reads from that instead. ${ }^{8}$ His face is animated, and he underlines the words of the poem with facial expressions and grimaces and by using his left hand to mark the rhythm and underscore important words. Here the body clearly guarantees the presence and authenticity of the performance, since Ginsberg's orality and gestures establish a lively and engaging performance, and, more importantly, so do his actions of looking directly at the audience before he starts reading and very soon after that looking up and smiling again. Most of the time his face is bent down towards the book, though, and he looks up at the audience only occasionally, which makes his facial gestures less visible 
for both the audience and the viewer of the film. But Ginsberg demonstrates the combined value of the voice and arm and hand gestures and how they can animate a performance. His hand gestures are, accordingly, the most flamboyant part of his performance; they mark the rhythm, flapping like a bird, and his index finger reprimands the audience and he points at one of the other Beat poets on the stage. He gets more and more agitated and heated, and then he abruptly stops his reading to calmly ask 'Andrei' if he would like to read.

\section{Performance as a qualified medium - Institutional framing}

In these three examples, we can see how the body language of the performers contributes to and enhances our understanding of the spoken word and also guarantees the necessary authenticity and presence of each performance. One important question remains, though: why do we interpret these activities as performances at all? And how do we know that we have to expect that poetry will be performed? We are not only watching performers speaking and using their bodies; we are also seeing a body acting out 'something' in the spatiotemporality of a performative space in front of an audience.

Lydia Lunch performs in front of an audience, which makes it possible for us to rapidly determine the situation as a performance of some sort, even if we are not part of the co-present audience but are only watching the YouTube clip. There appears to be no proper stage, but rather a performative space around her, a clear division between the performer and the audience, which situates Lunch as a body in a certain space at a specific time. We must add here that the microphone, besides being a technical device (which will be discussed next), also enlarges the performative space, simply because it ensures that Lunch will be audible from further away. Despite this, we still have to decide if she is performing at this moment as a rock artist or as an author, and because there are no instruments on the stage, the conclusion must be that she is very probably performing as an author. This is immediately confirmed when she starts to speak, because first of all she does not sing, and second she addresses the audience as 'ladies and gentlemen' at the beginning of her performance. The rest of the stage lies in darkness, and we can only distinguish something that seems to be a table and that eventually turns out to be a Xerox machine, with crumpled sheets of paper on it. This implies that the only valid criteria for this being performance is the situation itself: we can see an individual in front of other individuals, speaking words that by convention usually introduce performances of other sorts (vaudeville, circus, etc.). There is of course something else that causes us to make this decision, which is drawing on the contextual qualifying aspects of Lydia Lunch being known as an actress, poet and rock artist. She is also a spoken-word artist and very likely it is poetry we will hear, and consequently she is the main attraction and not just the person announcing the show.

Henry Rollins doesn't perform his poem on a stage, or in front of a copresent audience, but it is clear to anyone who watches the film that it is still a performance, because the staging, with its carefully fashioned soundscape, 
makes it an ephemeral presentation that occurs at a specific time and in a specific space. Having prior knowledge of Rollins is of course of great importance, but even someone who does not know that he is a rock singer and author would still recognize the situation as a performance. Why is that? Well, we see Rollins as if he was on stage, addressing an audience, so the situation is fairly similar to that of Lunch's performance even though we do not know whether there is an audience in front of Rollins or not. We sense a performative time more than a performative space, because Rollins begins with his eyes closed and then suddenly opens them. So even in this case, the framing of the performance makes us decide that this is the qualified medium of performance, and after hearing Rollins speaking, we also deduce more or less instantly that it is a lyrical performance, that is, he is not singing or performing drama. In Rollins' case, the fact that we cannot see the microphone, a technical device, in the film, makes the performance more direct, which reduces the performative space and makes it even more claustrophobic because the head of the performer is so close to the audience.

Allen Ginsberg climbs onto a traditional stage when it is his turn to read. The stage is not just any stage, but one of the main performance stages and perhaps the most famous in the UK, the Royal Albert Hall, where artists have performed for about 150 years. It is the exemplary institutional frame, not least because most members of the audience sit in the stalls and balconies, like the audience should in a theatre. Unlike Lunch and Rollins, Ginsberg reads from a manuscript and then from a book, devices that work as genre markers, making us qualify the media type faster. At the same time, they are intermedial references that are included in this qualified medium, and as technical media of display they become part of the performance. Before Ginsberg starts reading, he turns over the sheets of paper, decides which poem to read and slams the remaining papers down on the music stand; he hesitates slightly until the audience stops booing the poet who has just finished performing, and then he starts to read forcefully from the book. It seems as if several cuts may have been made in the film, because in one frame Ginsberg is sitting down throwing pieces of paper at the partner of the poet who has just performed, Ernst Jandl, ${ }^{10}$ and in the next he suddenly stands up in front of the microphone. We interpret this lacuna as editorial, because the booing seems to be superimposed on the later frame of Ginsberg, so in reality there must have been a short pause before he entered the stage. The same happens with the sheets of paper he seems to start reading from, because when he actually reads, it is from the book and not from the sheets that we have seen first, which means that there must have been an editorial cut here as well. It is interesting to reflect on the interaction between the audience and the poet, because Ginsberg so clearly reacts to the audience and stages himself as a serious poet. He hesitates while they are in an uproar booing, and he starts reading when he gets a signal that the audience has started to calm down, which forces all of the audience members to do so and then even more gradually to become quiet and start to listen. 


\section{The performer's intermedial relation with other media}

All of the performers we have discussed interact with different kinds of media and devices. Some of these technical devices or physical media, such as Lunch's microphone or Ginsberg's book, are also qualifying aspects of the lyrical performance or poetry-reading. The choice of device in itself indicates whether we can expect a lyrical performance or a performance of poetry, but other media are also involved in these performances.

The main technical media in the case of Lydia Lunch are fairly simple to identify: first of all, she holds a microphone in her right hand through which she addresses the audience, so this medium is necessary for the performance itself. The microphone in Lunch's hand is therefore a qualifying aspect of this kind of modern performance. There is one more technical medium in all three examples, however, which we do not usually reflect on, because this medium is more or less 'transparent': light. All three shows are illuminated to various degrees, which can be most clearly distinguished in the case of Lunch, because she definitely has a spotlight focused on her - highlighting her and putting the audience in shadow. ${ }^{11}$ And in the case of this film-recorded performance, the video is a transmediation of Lydia Lunch's performance. Video technology changes the modalities of the performance significantly; most notably, those viewing the video clip are not attending a unique event with 'free' spatiality but have access to a media product that displays a performance, but that in itself is sequential and repeatable and the visual and auditory experience is decided by the position of the camera (and the recording microphone).

When it comes to Henry Rollins, we can't see devices such as microphones, cameras and so on, and his performance is staged in a closed room. It seems as if there is no co-present audience in the room; instead, the film extends the performative space to include us as part of multiple video audiences. Even if there are no spotlights visible, light contributes to the performance. Rollins is filmed in front of a projector screen (another technical medium of display), on which an old-fashioned slide projector displays amateur slides (according to the sound, which is clearly audible and part of the performative space). These images are obviously chosen to contrast with Rollins' reading of 'Family Man', and therefore they add a communicative level to the embodied message, since they show scenes that could be found in any conventional family photo album (the qualified medium of family slides). These photos work in contrast to Rollins' aggressive and threatening performance, which sets the scene in two ways: first of all, they display an atmosphere of naiveté and harmony that is uncanny (in the same way as in David Lynch's movie Blue Velvet, released in 1986); second, they give depth to Rollins' anger, because he so obviously attacks what they depict. There is one more medium in his performance, a circular sound whose source is hard to determine, but it is similar to the sound of a metronome or a clock with its rhythmical markings. The sound is more industrial and therefore more aggressive, though, so it is probably being produced by something other than a metronome or clock; in any case, the circularity and simplicity suggest repetitiveness, boredom and menace (the sound is louder before and after 
the performance, which shows that the sound has been edited to create a particular effect). It is hard to decide what qualified media type the basic media type of organized sound belongs to in this case, but the function may be one of two kinds: maybe Rollins wanted a rhythm to read to because he is a musician, but it is more likely that it was chosen to intensify the atmosphere, which is both threatening and tedious at the same time.

Allen Ginsberg is filmed from a distance as a full figure, a half figure and as a close-up on stage; there is a microphone standing in front of him and he also has, like the other poets who perform before him, a microphone hanging on his chest, both of which probably amplify the sound and are recording the poet. The fixed microphone augments the performative space and reduces the poet to an appendage to it, since he so clearly directs himself to it from a slightly bent-over position.

\section{The media transformation of the live performance}

When we analyse live performances, we are utterly dependent on the recorded sounds and images, because most people cannot attend a particular performance that is only going to take place once. And even if technical media had been used for these recordings, we would still have been at risk of not being able to access them so easily if the internet had not been developed, and with it social media such as YouTube. The media products discussed here thus involve several levels of transmediation and media representation. All three examples of live performances are analysed by way of film clips uploaded on YouTube. The kind of media we discuss next as augmenting and documenting media are by no means last in a hierarchical order, but rather the opposite, as they are the level of mediation that we are usually most aware of and that are discussed in terms of mediatization (Auslander 2008 [1999]).

However, seen from an intermedial perspective, live performance is already a media product; it uses the body as a basic medium and a technical medium of display that expresses the performance in movements and in spoken language together with extra-verbal oral utterances and gestures. The stage and the audience as qualified media indicators are the levels of mediation that make us decide what genre we are looking at and/or listening to, and this media product is then transmediated into a recorded performance, permitting us to analyse the live performance. Both film and sound, recorded by the camera and/or the microphone, have the properties of extending or augmenting the performative space and time. When we study live performance, we interact with a media product of film while focusing on the media product that is transmediated. This is a bit like reading a translation of a novel that we cannot read in the original. Thus, we have to consider how the transmediation affects our experience of the performance, which of course makes it important for our decision about which kind of qualified medium we are watching. However, because they do this to a minor extent in relation to the stage/audience divide, we do not explore in the next sections the YouTube clips in relation to the social media context, but instead focus on the transmediation of the performance. 
Filming introduces a question about immediacy, which is the kind of media interaction that does not pay attention to the presence of the medium but only interacts with what we perceive as 'content'. Lunch is filmed head-on and the shots are edited to include her as a full figure, a half figure and a close-up. This style is used throughout the entire performance, and the only cuts involve shifting between two different cameras. When we watch the performance on a screen as an edited film, we are attending a different kind of performance from the one we would be attending if we were part of the co-present audience. The media representation of a live performance, however, transmediates many of the basic media types of performance, such as orality, gestures and the speech of bodies that are also moving, and hence we are able to decide which kind of performance we want to watch. Though the experience of the performance changes, the film makes it possible for us to watch Lunch's performance after the real-time performance has ended. We do not know if the microphone generates the sound for the film, or whether the camera does, which seems more likely, or both, but this had no real consequences for our previous analysis as we focused on analysing the speech and orality of the live performances and not their transmediation by means of sound recording (and sound editing).

Rollins is filmed head-on and in close-up. There are no cuts between different camera perspectives, and in this static perspective we can perceive the changing slides in the background. It seems as if the camera provides the sound as well because we can't see any handheld or pinned microphone, but sound has been recorded (and edited) in a way that makes it possible to discern the interaction between Rollin's speech, the sound of the slide projector and the rhythmical sound effect. Without the filming, though, it would not be possible for anyone to analyse his performance, since it seems to have been staged for the camera only.

In the case of Ginsberg, the recording film cameras and microphones are not visible, but the film has been heavily edited and cut before being put together again as a whole. According to a comment on YouTube, the film was cut considerably to form the circa 25-minute long clip we can watch now, because the readings went on for hours. This seems to be correct, because Ginsberg's reading is far too short if we consider his status as one of the main Beat poets at the time, and we have already mentioned the visible cuts in the reading. What is striking, as we have disclosed earlier, is that although the film makes it possible for us to experience parts of the reading, at the same time we are more exposed to someone else's editing of the same event. What we see is not documentation straight off, but a narrative that has been planned and realized for a film audience by an anonymous film editor. ${ }^{12}$ Thus, although the film recordings at first glance seem to be transparent, we can see when we look more closely how the media characteristics of film inevitably transform the media product of a live performance.

\section{Poetry performances: Concluding words}

As we have seen, the body is not the only medium in a performance, but it reacts to and interacts with other media, some of which are constitutive of our 
decision concerning which qualified medium or which genre we are watching. Other media are not part of the performance but make it possible for us to see it they augment the performative space, but they also transform and transmediate it. Through a combination of the perspectives of performance studies and intermedial studies, we have achieved a richer analysis, which focuses on the performer's body as a medium and the presence it establishes. At the same time, the body is discussed in its multimodal complexity and in terms of its intermedial relations. Whereas performance studies are inclined to disregard various media because they are seen as being hindrances to the necessary presence that a performance must establish, according to intermedial studies, we can now see that mediation and mediatization are necessary means to establish the very same presence. At the same time, it is not enough to focus on the different media involved in a performance, because one then tends to miss the presence of the performer and sometimes even the message. It is therefore clear that intermedial studies can offer a very useful toolbox when it comes to different kinds of analyses, and especially so when it comes to analyses of live arts.

\section{Football as an intermedial performance}

A ball being playfully kicked by a few players towards a goal seems enough for us to recognize a football game even when it is played informally in a backyard or a street. But the institutionalized, professional game follows a set of specific rules. Twenty-two players who form two teams compete in a stadium for the highest score by trying to get the specifically designed ball into the opponent's goal. Each move is carefully observed and analysed by the referees, an audience and multiple technologically extended eyes and ears. Despite all of the rules and control, a lot of training and well-planned strategies, a football game is an exciting performance without being too predictable. A large audience is therefore emotionally engaged, cheering in a stadium, in pubs, in city squares or at home. Football is transformed into various qualified media products such as video games (FIFA 15), books, films and music videos about football, or football songs in different languages.

In this part of the chapter, we examine the criss-crossing multimodality of an international football match as a mediatized public performance and as qualified media products. The social and political qualities of football cultivate specific social identities that are inseparable from neoliberal consumer culture. By reading this section, you will gain a more differentiated perspective on how cultural artefacts in our (post)modern culture are enfolded in complex mediatizing processes.

\section{Football: A game, a form of play or a performance?}

What do we gain when considering football as a performance and not only as a game or a form of play? How does an intermedial approach differ from the statement 'That's football: sometimes the better team wins' (attributed to the German professional player Lukas Podolski, quoted in Werron 2015, p. 24)? 


\section{Per Bäckström et al.}

When played informally, the game can be performed at any time, by any number and any kind of player; bins can be either used to mark goalposts or instead of a ball. This type of competitive leisure activity may be studied in terms of traditional play theory, as done by the Dutch historian Johan H. Huizinga in his seminal book Homo Ludens: A Study of the Play Element in Culture (Huizinga 1949). He regarded the human species as players, homo ludens, and culture as a purposeless and self-referential play. Football favours the educational ideals of fair play and sociability while presuming that football involves the truthful play of free people making free choices. However, it is doubtful if modern elite football equals this idealist view. Elite football is not only a game; it is also a competitive performance following inherent structures of power and commerce.

Football has been criticized not only for being a mass media event but also for its sociopolitical, military and ideological issues concerning national identity (Law 2014, p. 30). International football games are unmistakeably similar in some ways to military battles: players have to strictly obey the rules of the game. A game is often mentally dominated by aggression and violence. Moreover, it is embedded in national rituals such as the waving of national flags or the singing of anthems or national football songs. International football games are both multimodal performances and qualified media products. They affect the audiences and they (re)produce, at the same time, particular antagonistic sociopolitical tensions between competing and cooperating groups and norms. Football games and political power struggles cannot be disconnected. No wonder that football is a common metaphor for war. It is not only applied to the Gulf War in 1991 but also to other ideological and cultural battles foregrounding antagonistic arguments.

\section{A football performance as a qualified multimodal medium}

Let us start by focusing on the complexity of a football game when it is performed in the material and the spatiotemporal modality of a stadium. When attending such a performance, we interact with (1) the materiality of the stadium, (2) the materiality of moving bodies and (3) the materiality of multiple integrated technical media of display. The latter dissolves the opposition between football as a live performance and as a media product.

\section{The sociopolitical impact of the stadium}

The stadium is not a container in which a football game, as an aesthetic media product, is materialized. Rather, as a technical medium of display, the stadium institutionalizes football by giving it an economic value and by conditioning the social gathering for the identity formation of football fans.

In general, the stadium creates a material borderline between the inside and the outside, between the football performance that promises a unified entity and the everyday reality outside. Similar to a theatre, the stadium seems to offer a self-referential performance, controlled by its own rules enclosed by the 
architectural frame. It invites the audience to immerse itself in the enchanting and meaningful acts of a symbolic world. This perspective allows us to analyse football with the Greek concept of catharsis. Traditionally, it promises a releasing and cleansing of the spectators' emotions or violent affects. However, this idealistic concept presumes a clear separation between the safe, ordered and meaningful play-world inside and the contradictory 'real life' outside.

Meanwhile, a modern stadium, such as the German football team Bayern München's Allianz Arena, is more than an architectural frame. The aesthetically designed roof over the stands offers not only a material shelter. Rather, it integrates many technical devices, such as the lighting, microphones and cameras; most of them invisibly for the spectators. This functional equipment strengthens the visual and acoustic details of the events for the spectators. However, it also gives an advantage to those who observe and control the movements on the stands, the pitch and the surroundings of the stadium. Moreover, the installed microphones foreground the typical soundscape of football, the cheering and whistling noises. This technically enhanced sound intensifies the fans' emotional involvement and guarantees the authenticity of the live game. However, the characteristic soundscape of fans is also added as an isolated component to so-called ghost games to improve those media representations of football games that are not played for real spectators. Technological devices can be used to manipulate or simulate the interactivity of the game.

Not only the soundscape but also the inner and outer safety fences strengthen a clear border between the closed world of a football game and the otherness of an open and unstable 'reality'. This antagonistic thinking between the inside play-world and the otherness of the life-world outside affirms the process of othering, that is, the difference between 'us' vs. 'them'. However, having in mind that all people experience the game and the world differently, it seems better to assume a 'pluralization of life-worlds' both inside and outside the stadium (Bausinger 2000, p. 56). Some act as fans, supporting one team or the other, and some are critical observers of both teams or just contemplate the aesthetics of the play.

The sociopolitical impact of the material and spatial organization of the stadium shapes the live experience of a football match. For instance, the stands at the goal ends, commonly called the Kop, are the cheapest places to watch a match because of their limited view. They are also the ones with the closest connection to the favoured team and their other fans. Thus, these seats support the feeling of identity with one group in competition with the fans of the other team. Already the term Kop introduces another popular war metaphor into the world of football (Odell 2019). It derives from the similarity between these fans and the soldiers that had lined up in front of the steep hill of Spion Kop in the Second Boer War (1899-1902) (Pakenham 1979).

The distinctive material and spatial organization of the spectators in the stadium produces social differences as the more distanced and seated stands are also more expensive. The sociopolitical aspect becomes even more recognizable when regarding the shifting organization of the stands in the historical context. 
In 1989, a game in the overcrowded Hillsborough stadium became a total disaster, ${ }^{13}$ in particular, due to the poorly organized policing. However, thereafter, all UK stadiums were reshaped into modern all-seater stadiums. This reduced the intensity attributed to the Kop but diversified also a former mostly male working class audience. It opens the stadium not only for women and children but gave also higher-ranking groups separated and comfortable seats of the VIP areas in the 'sky boxes' to see from above without being seen. On the other hand, the material-technological organization of space through barriers and fences now delimits the visitors' coordinated tactile movements (such as swaying and surging down the slope). The safety equipment of the stadium domesticates and disciplines human behaviour. and visitors can be tracked and observed. Seen from the view of the technological safety system, all visitors are considered to be 'rioters' (King 1998, p. 161).

\section{The materiality of the body}

During a football performance, bodies interact with other bodies in a spatiotemporal and sensorial experience and a constant meaning-making process. The body, as a basic medium, becomes a mode of production and is seen as an 'object' that transforms a place into a stage by acting and interacting with other bodies (see Chapter 7). Even a football performance constructs such a dynamic interplay between the bodies performing as subjects and objects both on the pitch and on the stands. Even for the intensive but limited time of the performance, football has some qualities of the theatre.

During a performance in a stadium or a theatre, bodies represent different roles. On the pitch, the players and the referee are actors who are performing their roles according to their specific function and spatial position on the pitch. They are 'goalkeepers', 'defenders', 'midfielders', attacking 'forwards', or 'strikers'. The fixed number of the dramatic actors matches that of the players. They are identified by their football kit, which is comparable to the ancient masks that used to be seen on the stage. The identity of the football club is symbolized by the emblem and colours on the kit, while the numbers are indexical signs pointing roughly to the player's position on the pitch.

\section{The 'agon' of a competitive performance}

When we compare a football performance with a theatrical performance further, we also immediately see differences, such as the relevance given to the basic medium of words. Traditionally, verbal signs are prioritized when qualifying cultural media products and meaning. However, the intermedial performance discourse foregrounds the multimodal potentiality of creating meaning. Therefore, it also explores the non-verbal staging of football and its agonistic or competitive structure (agon is a Greek term for struggle) as an aesthetic event. The analogy between football and theatre is based on this 'powerful communicative poetics' (Pyta 2015, p. 262), also known as agon aesthetic (Borge 2015). 
In this case, the focus is on the structural similarities between the theatre with its staged aesthetic interaction (called praxis) and the football play as staged aesthetic performance on the pitch (called agon praxis). In theatre, the protagonist and the opponent, the antagonist, interact and push words and arguments in competitive dialogues back and forth (logos means both the word and the aesthetic of order). In football, the staged agon praxis intertwines the aesthetically interacting and competing bodies kicking and passing the ball into the opponent's goal. Thus, while the basic medium of the body organizes an agon performance, the beauty of composing an order $(\log o s)$ that guarantees the aesthetic of the game is not restricted to words. Instead, the order of a performance is constituted by the presence of bodily actions following the invisible rules of the game during the performance of embodied meaning-making.

For instance, the football protagonist Zidane, representing masculinity, power, and tactical knowledge, can figure as a tragic hero when competing with his antagonist Materazzi. ${ }^{14}$ Although Zidane intended his famous headbutt in 2006 as a punishment for Materazzi's verbal insult, this action was against the football rules. Zidane's tragic leaving of the pitch exemplifies the tragic agon aesthetic. Moreover, it implies also a competition between different rules and ethical codes of different time-spaces and cultural groups.

However, professional players, such as Zlatan, Beckham or Mbappé, can be regarded either as actors, heroes, protagonists or commodities. In any case, they are never private individuals. Rather, they always play at the front of the stage and brand themselves like movie stars and cultural icons. Football players are not any longer bound to a club by loyalty, but by money. Sold and purchased by different clubs, a football player is, like his kit, both a media platform for advertising and a commodity. Players increase their so-called transfer value not only through their success on the pitch but also through networking and mediatized discourses of sports journalism. Moreover, countless interviews on social media or TV, advertisements or fan discourses create dramatic narratives and myths. This discourse also intensifies the sociopolitical value attributed to specific players and football performances in capitalism.

\section{The body of the '12th man': The audience}

Despite the before-mentioned ghost-games, the atmosphere of a live football performance depends on the co-present audience. It participates as the so-called 12th man and creates the specific atmospheric tension between order and disorder in a stadium. As soon as you enter a stadium, you participate in the dynamic structure of a mutual and performative self-constitution: you choose a role such as critical observer, connoisseur, supporter, fan or ultra, and you participate as one of the multiple voices of an interactive communication. Some fans on the stands use their moving bodies as a basic medium to instigate group-based emotions. This affective communality often stipulates a rivalry and dissensus between different groups battling for the 'best' choreography. The multimodal fan performances consist of ritualized movements, such as cheering, 
handclapping, of instrumental and vocal sounds as well as of well-organized responding football chants. Thus, the noisy fan groups compete with the visual body performances of the players on the pitch. The specific atmosphere of a live performance affects the communication between the players and the spectators of which some groups so actively participate in the performance. This interplay creates the pluralization of life-worlds by shaping multiple sensual (rather than rational) meanings and emotions. In the social-relational situation in and outside the stadium, the performing players and the performing spectators elicit different forms of a mutually 'transformative aesthetic' (Fischer-Lichte 2008 , p. 38), ending in an 'emotional repertoire' of social bonding and identity formation.

\section{Football - Live performance and media product}

All technical media devices and media of display change the social experience of the space where football is experienced. The impact of diverse media technologies, used by the organizers to broadcast the play and by the fans to communicate, subdues an important traditional opposition: that between the idealized live performance of football in a stadium as an immediate and ephemeral experience of presence on the one hand and the qualified media product on the other. Usually, the media product is linked with the idea that the football game is merely a representation of a game and produced by the recording and disseminating media technologies. Even outside the stadium, at home in front of the TV or at the pub, the viewer can still experience the stadium's noisy atmosphere, either alone or with their friends.

However, this view needs to be reconsidered. The transmitting media technology constitutes an important part of the live experience in a stadium. To emulate the mediated TV show, the stadium improves the affective sensation of football also by incorporating and combining modern technical media: mobile video walls shall overcome the visual limits of a fixed, distanced pitch in the stadium. They provide the spectators with close-ups of the players, with the shifting visual frames of the cameras, and repetitions of scores and fouls. While the fans and the players are co-present in the stadium, the fans in the stands also watch the players on screens in the etymological sense of television (tele meaning far and visio meaning sight). Thus, the mediating sight percieved via the eyeball is mixed with the mediated sight that is framed through technical media. Thus, the stadium's technological elements do not only enhance the immersive effect of an autonomous football world. Rather, the only partly visible technological devices can also control the performance and change its 'natural' sensual perception. The microphones in the roof, for instance, stipulate the sound of the fans and the ball to intensify the immersive effect but repress other phenomena that disturb the order and unity of the play-world. Important are the cameras and the video assistant referee (VAR) that distribute information merely to selected groups rather than to all visitors and thus illustrate the agency and social power of technical media in its encounter with 
humans. The collected data of the VAR - interpreted by experts in a command centre, an elevated separate zone of power in the stadium, and transferred to the referee's headset during the game - exclude not only the spectators from the information for his decision making. More important is the fact that measurable technological data collected from an 'objective' position in the sky is given priority over the human decision making in a game, performed by humans according to ethical rules.

In these moments, technological media transform the human subjects controlling the technical media and the human subjects performing both on the pitch and on the stands into hybrid subjects/objects. The technical data collection becomes agency and a resource of social power that affects the players, the coaches and the audience. Technological data that cannot be seen with the naked eyes now shape how humans shall experience and evaluate the live performance of the game in front of them. Using the sociopolitical modality, we can interrogate the social power given to the technological media infrastructure, deciding what counts as 'neutral' or 'objective' information. This materiality of knowing can be used either in opposition to or in accordance with a mutual dependence on humans' rights and their ethical values.

\section{The commercialization of football}

'Modern football is highly commodified - something to be bought and sold to consumers' (Bale 1998). The physical space of the modern stadium transformed the ideal 'flow of the game' into a 'flow of money'. Due also to the increased costs for advanced technological devices, broadcast rights were sold to public or private channels. As fans constantly practise a highly valued loyalty to their local club and its stadium, they are the ideal consumers or fansumers that produce reliable data for the advertisements visible on high-tech LED screens alongside the pitch. In the all-embracing experience economy of popular culture, this commercializing practice creates a synergetic relationship between football, leisure and consumerism. Rather than being merely a game, football is intersected with the sociopolitical rules of the neoliberal and globalized consumer culture. Thus, it has also an ideal symbolic surplus value as a commodity.

The embodied experience of a football performance is always bound to a place, a time and diverse technical media. However, also public places other than the stadium can become attractive spatiotemporal and material frames for football. Lately, public viewing events are popular public spaces where huge mobile video screens provide an open-air football experience for a community of enthusiastic spectators. They provide the feeling of presence and of being there, similar to an experience in a stadium, and dissolve the opposition between a performance and a media product. However, these events never deliver neutral audiovisual footage. Any broadcasting of a live football performance reconstructs, frames, enhances and comments on the game and the affective atmosphere of the stadium. 
To conclude, the experience of immediacy and presence draws the feeling of authenticity from the collective experience of co-performing spectators rather than from the spatial and temporal closeness to the performing players.

\section{Spatiotemporal modality: Perception of time frames and the space of the turf}

We usually think that a game of football lasts for 90 minutes. However, if we look more closely, a football performance is staged in a relative rather than a fixed time frame. This time frame is set by the Laws of the Game (LOTG) and established by the referee. The referee directs the play with simple tools and symbolic signs of power. His or her body gestures and the sound of the whistle are audiovisual signs announcing the beginning and end of the playtime. The referee not only keeps the time but can add time for any unpredictable stoppage and two extra time slots of 15 minutes if a match has no winner at full time. Thus, the referee's position represents tension against the quantitatively measurable clock time, which is visually displayed in running numbers on digital screens. A football performance also makes us aware of the quality of time as an emotional resource; in particular, the last few minutes of the game or the extra time are periods of excitement. In an unexciting game, the quality of time is also negatively felt and made audible by the fans' sonic practice.

The space on the turf is outlined with several white lines, partly defining the surface of the playing field and dividing it into different zones. While these lines seem to limit the pitch to a two-dimensional surface field, the players' performances explore it as a three-dimensional stage: the players jump to attempt headers, for example. A particular use by Zlatan Ibrahimovic of the third dimension of the pitch and the aerodynamics of a ball can be appreciated for its elegance and aesthetic: against all probability, he scored with his famous overhead kick, called a 'bicycle kick', in 2012. ${ }^{15}$ The quality of time and space (kairos) and the player's body skills came together in a way that could not have been anticipated. In football, space is also closely linked to the time that players are in possession of the always-moving ball. The dribbling of the ball along the touchline of the pitch visualizes the different qualities of the space, as only the player, not the ball, is allowed to move outside the pitch, in between the pitch and the spectators. The value of this movement lies in the emotional closeness to the co-present audience, reinforcing their desire to 'play football together'.

So, multiple lines transform the pitch not only into a measurable space, distinct from the spectators, but also into different qualitative zones of intensity, such as the spaces close to the goal or the penalty area. Also, different tactical principles of creating and occupying space attribute special values to these zones. Often, the attacking team will spread out over the field to find an empty space in which to get a shot, while the defending team will strive to compress the space around the ball. Bayern München's player Thomas Müller is celebrated as the 'interpreter of space' because he can anticipate a qualitative time-space, kairos, fitting for a shot, and the right partner running into the right zone. Space, time, bodies and the ball create here a dynamic performative agency. 
The large stadiums and the attention paid to international football also attract political protest performances that make the inherent social rules and the Laws of the Game visible by disturbing them. Such an unexpected performance was organized by the Russian group Pussy Riot, as three of their members invaded the pitch in the second half of the 2018 FIFA World Cup Final match between France and Croatia. Dressed up as police and thus representing legal authority, they demonstrated the rules and structure of power that only become visible when they are disturbed. In this sense, the antagonistic game inside the space equals the game and the invisible power rules outside the stadium, in particular, in the Russian authoritarian regime where the official Russian media channels neither showed nor commented on this interference. Instead, the Russian internet forums rapidly created supporter groups to disseminate the political message of this otherwise suppressed invasion. This resistant performance of Pussy Riot exemplifies the potentiality of the dissemination of diverse technical media. Moreover, it illuminates the invisible policing structure of international football and the potentiality of the antagonistic rhetoric of 'we' and 'them' inherent in the competitive football performance. These aspects can be explored when analysing the space, time, materiality and technology of football performances in the modern stadium by applying the sociopolitical modality.

\section{Football as an intermedial performance: Concluding words}

This chapter explored international football as a multimodal performance played in various contested (time) spaces. While football enfolds the traditional concepts of an antagonistic game into the broader intermedial concept of a qualified media product, the power structures, inherent in the material-technological modality of the stadium, modify the encounter of the football fans with the performing bodies of the players during the limited but dynamic time-space of a football game. Rather than regarding the stadium as a neutral container for the live performance, the material and technological aspects of the stadium actively organize the spaces along with the invisible but important sociopolitical power structures.

\section{Notes}

1 When we refer to the body in this chapter, we are referring to the performer's body but choose to use only the word 'body' to avoid making the text repetitive.

2 See the BBC website for a list of ten great songs that got away with nonsense: https://www.bbc.co.uk/music/articles/2d67dd79-7603-46ef-ba55-b46cd2884f8b (accessed 1 October 2021).

3 See Lydia Lunch's performance at: https://www.youtube.com/watch? $=\mathrm{gDvWrp}$ xpJ8U (accessed 1 October 2021). We use the conventions of spoken word and call the performed text a poem.

4 How the performance is filmed makes it nearly impossible to observe the reactions of the audience. We therefore exclude audience reaction from the analysis, which will focus on Lydia Lunch as a performing body. 
5 See Henry Rollins: https://www.youtube.com/watch?v=r3S-IuxseAI (accessed 1 October 2021).

6 There is a slight chance that Rollins reads the poem from a written version of it placed somewhere in front of him, but he had performed the poem frequently with his rock group Black Flag, so it is more likely that he knew it by heart.

7 Allen Ginsberg reads at the Royal Albert Hall in 1965 (the original clip withdrawn, this one shows the reading also, though): https://www.youtube.com/watch? $\mathrm{v}=\mathrm{JiQQ} 0 \mathrm{Dljj} 4$ (accessed 1 October 2021)

8 It is hard to decide, but it seems as if the poets are reading from a protruding stage, because Ginsberg turns his face in different directions and gestures energetically in the same directions.

9 Her very modern reading has - paradoxically - ancient roots in the 'bard battles' of, for instance, the Celtic or Scandinavian traditions, where one kind of battle involved competing to see who could insult the other party the most harshly.

10 His partners were also poets. The mockery of concrete poetry was probably experienced as a threat to the dead serious Beat poets, who, even though they sometimes jest, clearly want to give the impression of being Poets.

11 When it comes to Rollins, it is hard to discern whether the light is natural or comes from another source, and Ginsberg stands on a stage that has ordinary stage lighting.

12 According to one comment, Peter Whitehead filmed the poetry-readings, but there are no indications about who edited the film, even though it was probably done by Whitehead too.

13 You can find a short introduction to the disaster in the short video titled What happened at Hillsborough? by BBC News. Available at https://www.youtube.com/wa tch? $=$ MNS26Oj9B4o (Accessed 1 October 2021). For more critical background information, see Pyta (2015).

14 You can see Zidane's headbutt, an aggressive reaction caused by Materazzi's offensive words about Zidane's mother or sister, here: https://www.youtube.com/watch?

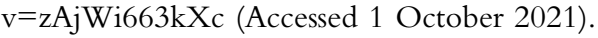

15 You can see this famous bicycle kick here: Zlatan Ibrahimovic's Famous 30-yard Bicycle Kick vs England: https://www.youtube.com/watch?v=RM_5tJncHww (Accessed 1 October 2021). For more details about the performance of this skilled kick, see O'Brien (2005, p. 69).

\section{Further reading}

Agamben, Giorgio. 2018. Karman: A brief treatise on action, guilt, and gesture. Meridian, crossing aesthetics. Stanford: Stanford University Press.

Auslander, Philip. 2008 [1999]. Liveness: Performance in a mediatized culture. London/New York: Routledge.

Bal, Mieke. 2002. Travelling concepts in the humanities: A rough guide. Toronto: University of Toronto.

Barthes, Roland. 1981. Le Grain de la voix: Entretiens (1962-1980). Paris: Gallimard.

Chapple, Freda and Kattenbelt, Chiel, eds. 2006. Intermediality in theatre and performance. Amsterdam: Rodopi.

Fischer-Lichte, Erika. 2008. The transformative power of performance: A new aesthetics. London: Routledge.

Frith, Simon. 2002 [1996]. Performing rites: Evaluating popular music. New York; Oxford: Oxford University Press. 
Goldin-Meadow, Susan and Wagner Alibali, Martha. 2013. Gesture's role in speaking, learning, and creating language. Annu. Rev. Psychol., 64, pp. 257-283. doi:10.1146/ annurev-psych-113011-143802

Guérin, Michel. 2011 [1995]. Philosophie du geste. Arles: Actes sud.

Keevallik, Leelo and Richard Ogden. 2020. Sounds on the margins of language at the heart of interaction. Research on Language and Social Interaction, 53(1), pp. 1-18. doi:10.1080/08351813.2020.1712961

Kendon, Adam. 2004. Gesture: Visible action as utterance. Cambridge: Cambridge University Press.

Krämer, Sybille. 2014. Connecting performance and performativity. Does it work? In Laura Cull and Alica Lagaay, eds., Encounters in performance philosophy. Basingstoke: Palgrave Macmillan.

Velten, Hans Rudolf. 2016. Performativity and performance. In Birgit Neumann and Ansgar Nünning, eds., Travelling concepts for the study of culture (pp. 249-266). Berlin; Boston: de Gruyter.

\section{References}

Agamben, Giorgio. 2000 [1996]. Means without end: Notes on politics. Minneapolis: University of Minnesota Press.

Agamben, Giorgio. 2018. Karman: A brief treatise on action, guilt, and gesture. Meridian, crossing aesthetics. Stanford, California: Stanford University Press.

Auslander, Philip. 2008 [1999]. Liveness: Performance in a mediatized culture. London; New York: Routledge.

Austin, John Langshaw. 1962. How to Do Things with Words. Oxford: Clarendon.

Bäckström, Per. 2003. Aska, Tomhet \& Eld. Outsiderproblematiken hos Bruno K. Öijer. Lund: Ellerström (diss.).

Bal, Mieke. 2002. Travelling concepts in the humanities: A rough guide. Toronto: Univiversity of Toronto.

Bale, John. 1998. Virtual fandoms: Futurescapes of football. In Adam Brown, ed., Fanatics power, identity and fandom in football (pp. 265-278). London: Routledge,.

Barthes, Roland. 1981. Le Grain de la voix: Entretiens (1962-1980), Paris: Gallimard.

Bausinger, Hermann. 2000. Kleine Feste im Alltag: Zur Bedeutung des Fußballs. In Wolfgang Schlicht and Werner Lang, eds., Über Fußball: Ein Lesebuch zur wichtigsten Nebensache der Welt. Münster: Hofmann, pp. 42-58.

Borge, Steffen. 2015. An agon aesthetics of football. Sport, Ethics and Philosophy, 9(2), pp. 97-123.

Butler, Judith. 1990. Gender trouble: Feminism and the subversion of identity. New York: Routledge.

Chapple, Freda and Kattenbelt, Chiel, eds. 2006. Intermediality in theatre and performance. Amsterdam: Rodopi.

Derrida, Jacques. 1988 [1977]. Signature event context. In Limited Inc (pp. 1-24). Evanston: Northwestern University Press.

Dolan, Jill. 2005. Utopia in performance: Finding hope at the theater. Ann Arbor: University of Michigan Press.

Elleström, Lars. 2021. The modalities of media: A model for understanding intermedial relations. In Lars Elleström, ed., Media borders. Houndmills; New York: Palgrave Macmillan. 


\section{4}

Per Bäckström et al.

Fischer-Lichte, Erika. 2008. The transformative power of performance: A new aesthetics. London: Routledge.

Frith, Simon. 2002 [1996]. Performing rites: Evaluating popular music. New York; Oxford: Oxford University Press.

Glare, P.G.W. (red.) 1968. Oxford Latin dictionary. Oxford: Clarendon Press.

Goldin-Meadow, Susan and Wagner Alibali, Martha. 2013. Gesture's role in speaking, learning, and creating language. Annu. Rev. Psychol., 64, pp. 257-283. doi:10.1146/ annurev-psych-113011-143802

Guérin, Michel. 2011 [1995]. Philosophie du geste. Arles: Actes sud.

Huizinga, Johan H. 1949. Homo ludens: A study of the play element in culture. London, Boston and Henley: Routledge \& Kegan Paul.

Kendon, Adam. 2004. Gesture: Visible action as utterance. Cambridge: Cambridge University Press.

Keevallik, Leelo and Ogden, Richard. 2020. Sounds on the margins of language at the heart of interaction. Research on Language and Social Interaction, 53(1), pp. 1-18, doi:10.1080/08351813.2020.1712961

King, Anthony. 1998. The end of the terraces: The transformation of English football in the 1990s, London: Leicester University Press.

Law, Alex. 2014. Playing with tension: National charisma and disgrace at Euro 2012. Soccer \& Society, 15(2), pp. 203-221.

O'Brien, Richard. 2005. The ultimate sports handbook. Philadelphia: Quirk Books.

Odell, Joseph. 2019. The legend of 'Spion Kop'. Tales of two halves. https://taleoftwoha lves.uk/featured/legend-spion-kop (Accessed 15 August 2020).

Pakenham, Thomas. 1979. The Boer war. New York: Random House.

Pyta, Wolfram. 2015. Football memory in a European perspective: The missing link in the European integration process. Historical Social Research/Historische Sozialforschung, 40(4), pp. 255-269.

Velten, Hans Rudolf. 2016. Performativity and performance. In Birgit Neumann and Ansgar Nünning, eds., Travelling concepts for the study of culture (pp. 249-266). Berlin; Boston: de Gruyter.

Werron, Tobias. 2015. How are football games remembered? Idioms of memory in modern football. In Wolfram Pyta and N. Havemann, eds., European football and collective memory (pp. 18-39). Basingstoke: Palgrave.

Yeats, William Butler. 1996. The collected poems of William Butler Yeats. Richard J. Finneran, ed. New York: Scribner. 